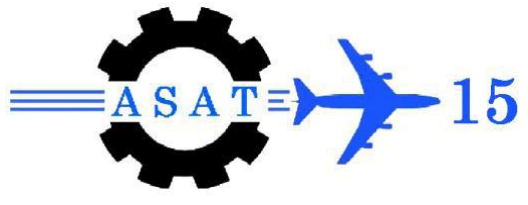

\title{
Experimental Characterization of Laser Shock Hardening of Aluminum
}

\author{
$\left\{\text { A. M. Darwish }{ }^{*}, \text { S. S. A. Obayya }\right\}^{\dagger}$
}

\begin{abstract}
Laser shock peening (LSP) is a surface treatment process for increasing the strength and reliability of metal components. Traditionally applied to aircraft parts, the technology also shows great potential for automotive and medical applications. The present study investigates the effect of multiple laser peening with and without coating on the hardness of aluminum alloy. The Vickers micro-hardness test is used to study the hardness of the alloy in different layer of the sample with different wavelengths and laser intensity. It has been initially found that metal hardness can be significantly increased with the increase of laser intensity and also with the increase of number of laser shots irradiated per unit area.
\end{abstract}

Keywords: Laser peening, laser shock peening (LSP), aluminum alloy, hardening, mechanical.

\section{Introduction}

In the previous four decades high strength, i.e. peak-aged aluminum alloys have been widely used in the aircraft, automotive, marine and construction industries, due to their low cost, good weight/strength ratio and high corrosion resistance[1-3], whereas with the addition of Sc and $\mathrm{Zr}$ superplastic properties, elongations to failure as high as about $2000 \%$ can be obtained [4]. However, aluminum alloys remain the subject of numerous studies due to their susceptibility to localized corrosion attack in more aggressive environments [ $\underline{5}, \underline{6}]$. Especially in chloride environment, peak-aged aluminum alloys tend to show increased susceptibility to pitting corrosion and stress corrosion cracking [6-8].

In order to reduce the surface roughness and deepen the compressive residual stresses distribution, many new peening technologies such as laser peening [9], cavitation shotless peening [10], ultrasonic peening [9] and microshot peening [111, 12] were developed. Among these peening technologies, laser shock peening (LSP) technique, as an alternative surface promising technology, was demonstrated and explored for first time by the early 1960 by Fairand and Clauer [13]. Initially, LSP was developed for the aeronautic industry as the method for the improvement of the resistance to fatigue cracking because LSP was considered as one of the most promising surface enhancement techniques in terms of its ability to induce surface compressive residual stress, surface hardness and microstructure modifications [9].

amahmoud@zewailcity.edu.eg.

$\dagger$ Centre for Photonics and Smart Materials (CPSM), Zewail City of Science and Technology, Sheikh Zayed District, 6th of October City, Giza, Egypt. 
For instance, LSP can be used to increase the resistance of a metal to crack initiation, extend the fatigue life, and enhance the fatigue strength [14-16]. This treatment is imparted by shockwaves resulting from the expansion of high-pressure plasma generated by an intense pulsed laser. [14-16] Most of the recent researches have been focusing on the effects of LSP processing parameters such as the pulse density $[\underline{17}, \underline{18}]$, impact number $[\underline{19}, \underline{20}$, geometry of sample [21], as well as laser spot size [22], surface integrity and fatigue life of alloys, but few attentions have been paid to the effects of LSP on the mechanical properties. A combination of high mechanical strength as well as good corrosion resistance has made Al based alloys a potential component in aerospace as well as automotive and shipping industries. Among them, Al-7075 has found widespread application due to good weld ability and mechanical strength [23-25].

In the present work we successfully performed LPwC on aluminum alloy Al-7075, emphasizing the effect of its hardness. The hardness of alloy can be significantly increased with the increase of the pulse energy up to $9 \mathrm{~J}$ and laser spot size in the range of few millimeters.

\section{Experimental of Laser Peening}

\section{Basic Principle}

Figure 1 shows a schematic representation of the basic process of laser shock peening (LSP) of samples. The basic principle behind LSP can be explained as follows. When a laser pulse is focused on a target which is immersed in water, a shockwave has to be induced in the target metal by generating plasma on its surface and the target surface layer evaporates instantaneously. The vapor continuously absorbs the laser energy for the entire pulse duration. This process converts the vapor to high temperature plasma. The water layer traps the highly expanding plasma towards the target surface and introduces intense shock waves of peak pressure in the order of several GPa [26-32]. At laser intensities exceeding $10^{10} \mathrm{~W} / \mathrm{cm}^{2}$, a shockwave is generated due to the ignition and explosive expansion of the plasma. The plastic deformation caused by the shockwave while propagating through the metal results in the hardening of the metal surface and the generation of a surface with residual compressive stresses. The effect of the shockwave can be enhanced by coating the surface of the target metal with a confining layer that is transparent to the laser beam [30]. The use of such a layer leads to an increase in the intensity of the shockwave because it prevents the laser-produced plasma from expanding rapidly away from the surface, thus creating a high-amplitude shortduration pressure pulse. In laser peening, including pulsed laser peeling, water, quartz, or glass is generally used as the transparent layer.

In practice two different LSP processes are known [33]; first uses protective coating or absorbent layer in order to prevent the material surface from melting or being damaged. The coating is usually formed with a black paint or Al foil prior to laser irradiation, and the remaining coating is removed after the treatment. The other one called laser peening without coating (LPwC) was discover in 1995 [34]. In general both LSP processes require a unique high power density, high repetition laser, which enables plasma generation at the moment of the interaction of laser light and propagation of shock impact waves in the material [35, $\underline{36}]$.

\section{Materials}

Test samples of $4 \mathrm{~cm}$ radius were prepared from $30 \mathrm{~mm}$ thick $\mathrm{Al}-7075$ by electric discharge machining (EDM) wire cutting. 


\section{Experimental setup}

Figure 2 shows the schematic representative of the experiment setup. A nanosecond laser system (POWERLITE ${ }^{\mathrm{TM}}$ Precision II 8000, Continuum laser, etc.) is used in the experiments. The fundamental wavelength $(1064 \mathrm{~nm})$ was frequency doubled in BBO crystal (SHG) to $532 \mathrm{~nm}$. Both laser beams are plane polarized after passing through a polarizer in the laser system. The full width at half maximum (FWHM) of the laser was fixed to be $7 \mathrm{~ns}$ at a nominal wavelength of $1064 \mathrm{~nm}$ through Q-switch mode operation and at the repetition rate was $10 \mathrm{~Hz}$. The focal length is measured to be $7 \mathrm{~cm}$. The average laser fluence is varied from 0.1 to $0.9 \mathrm{~J}$. An electric drier was placed near the lens to avoid damage caused to the lens because of water spillage at the time of peening. The sample was fixed on a holder which rests on a computer controlled $\mathrm{XY}$ translation stage that can move in the $\mathrm{X}$ and $\mathrm{Y}$ directions during the peening process. To assess the hardness across the sample region, hardness measurements shown in Figure 5 were taken using a micro-hardness machine (Shimaduz, micro-hardness).

The experimental parameters such as pulse energy $\left(E_{p}\right)$, laser spot diameter (D) and laser pulsed density $\left(\mathrm{N}_{\mathrm{p}}\right)$ of $\mathrm{LPwC}$ were maintained as listed in Table $1 . \mathrm{E}_{\mathrm{p}}$ is tuned with a variable delay between oscillator and amplifier of $\mathrm{Nd}$ :YAG laser, and $\mathrm{D}$ is adjusted by varying the distance between the lens and the sample. In case of flat samples, $\mathrm{N}_{\mathrm{p}}$ is simply determined with the driving speed of the sample in the $x$-direction and the step size in the $y$-direction, which shows the typical procedure of laser irradiation on plate samples.

\section{Result and Discussion}

\subsection{Surface Properties}

The external appearance of the aluminum alloy Al-7075 sample before and after LPwC is shown in Figure 3. The surface color changed from metallic to grayish at the instant of laser irradiation in an aqueous environment. This must be caused by the reaction of the surface with nascent-state oxygen supplied from the water decomposed by active plasma and the intense electric field of the focused laser pulse. [37].

\subsection{Work Hardening}

Work hardening effect of LPwC was evaluated based on micro-hardness analysis. Depth profile of micro-hardness is presented in Figure 4. For each depth, five measurements were taken and the average value is considered for discussion. Standard deviations of the trials were included in the graph as error bar. The Vickers micro-hardness measurement data of the aluminum alloy Al-7075 surface is summarized in Figures 5-7. Compared to the unpeened material, the hardness value of laser peened specimen reported a maximum improvement of $80 \mathrm{HV}$ near to the surface which representing the double increasing of hardness.

Figure 5 shows the Vickers micro-hardness of the aluminum alloy Al-7075 surface as a function of the energy fluence for nanosecond laser irradiation at infrared region $(1064 \mathrm{~nm})$ and visible region $(532 \mathrm{~nm})$. We can observe that laser irradiation caused a change in the hardness, as indicated by the plastic deformation in Aluminum. The nanosecond laser has the potential to change the mechanical properties of Aluminum. The hardness of the surface increases linearly with the energy fluence in both cases of irradiation but the IR-irradiation $(1064 \mathrm{~nm})$ laser was slightly better at hardening. 
A comparison of the depth profiles (relation between hardness and the depth from the surface of sample) for both laser beams is shown in Figure 6. In the experiments, the energy fluence was adjusted to be $0.9 \mathrm{~J}$. The dashed line in this figure indicates the normal hardness before laser irradiation. Since the nanosecond laser does not interact with the laser-produced plasma, the plasma does not absorb any laser energy; therefore, the entire energy of the laser is deposited on the target material.

A Vickers micro-hardness as a function of number of pulses was illustrated in Figure 7. From the graph, it is clear that the hardness of materials increased as increase of number of pulses. We found the largest magnitude of the micro-hardness resulted from Nd:YAG (1064nm) as the number of pulses increased rather than from Nd:YAG $(532 \mathrm{~nm})$. However, in case of unpeening, the hardness of the material remains without any change. The increase of the magnitude of the micro-hardness in case of Nd:YAG $(1064 \mathrm{~nm})$ is due to the effect of the high intensities of the laser ablation by fast laser which leads to heat conduction, melting, evaporation, and plasma formation. Then, the shockwave is produced and the hardness is increased. Therefore, the time of ablation and plasma formation are increased by increasing the number of shots. However, when the number of shots is increased more than 300 shots, the plasma is finished and the saturation occurs. Therefore, the hardness cannot be further increased and saturation occurs as shown in figure. Moreover, the infrared absorption is just heating of the surface since it increases molecular vibrational activity. However, the infrared is less strongly than visible light in energy. So, the infrared radiation does penetrate the surface and produced shockwaves further than visible light. So, the effect of hardness in case of infrared is higher than that if visible.

\section{Conclusion}

In summary, laser peening without coating (LPwC) was successfully performed on Al-7075 alloy using Nd:YAG laser to investigate the feasibility of nanosecond laser shock peening by using the fundamental wavelength $(1064 \mathrm{~nm})$ and its second harmonic $(532 \mathrm{~nm})$. It is found that the surface hardness of Al-7075 alloy increased approximately linearly with an increase in the energy fluence and number of laser shots irradiated per unit area.

\section{Acknowledgement}

The authors acknowledge the financial support of Center for Photonics and Smart Materials (CPSM), Zewail City of Science and Technology.

\section{References}

[1]. J.B. Bajat, I.M., Z`. Jovanovic' , R.M. Janc`ic'-Heinemann, M. Dimitrijevic' , V.B. Miškovic'-Stankovic' Corrosion protection of aluminum pretreated by vinyltriethoxysilane in sodium chloride solution,. Corros. Sci. , 2010(52): p. 10601069.

[2]. C.N. Panagopoulos, E.P.G., A.G. Gavras, Corrosion and wear of 6082 aluminum alloy. Tribol. Int. , 2009(42): p. 886-889.

[3]. Vargel, C., Corrosion of Aluminum. Elsevier Science, San Diego, USA, 2004.

[4]. A. Smolej, B.S., B. Markoli, D. Klobc`ar, V. Dragojevic' , E. Slac`ek, Superplastic behaviour of AA5083 aluminum alloy with scandium and zirconium. Mater. Sci. Forum 2012. 706(709): p. 395-401. 
[5]. M. Trueba, S.P.T., Study of Al alloy corrosion in neutral $\mathrm{NaCl}$ by the pitting scan technique. Mater. Chem. Phys., 2010(121): p. 523-533.

[6]. Szklarska-Smialowska, Z., Pitting corrosion of aluminum. Corros. Sci. , 1999(41 ): p. 1742-1767.

[7]. H. Ezuber, A.E.-H., F. Shawesh, A study on the corrosion behavior of aluminum alloys in seawater. Mater. Design 2008(29): p. 801-805.

[8]. T.M. Yue, L.J.Y., C.P. Chan, , Stress corrosion cracking behavior of Nd:YAG lasertreated aluminum alloy 7075. Appl. Surf. Sci. , 2006(252 ): p. 5026-5034.

[9]. Montross CS, W.T., Ye L, Clark G, Mai YW. , Laser shock processing and its effects on microstructure and properties of metal alloys: a review. . Int J Fatigue, 2002(24): p. 1021-1036.

[10]. Dan O, H.S., Cavitation shotless peening for improvement of fatigue strength of carbonized steel. Int J Fatigue, 2003(25): p. 121712-22.

[11]. O., K., Fatigue life enhancement of aluminum alloy for aircraft by fine particle shot peening (FPSP). J Mater Process Technol 2011(211): p. 1395-1399.

[12]. Harada Y, F.K., Haga S. , Influence of microshot peening on surface layer characteristics of structural steel. J Mater Process Technol, 2007(191): p. 297-301.

[13]. R.M. White, Generation of Elastic Waves by Transient Surface Heating. J. Appl. Phys., 1963(34): p. 2123.

[14]. Ye, K.D.a.L., Laser shoReferences shock peening. CRC press WP, Chapters 1 and 2, 2006.

[15]. P. Peyre, L.B., X. ScherpeWP, Scherpereel, and R. Fabbro, J. Mater. Sci., 1998(33).

[16]. Y. Sano, M.O., T. Kubo, N. Mukai, M. Yoda, K. Masaki, and Y. Ochi, Mater. Sci. Eng., 2006(4417).

[17]. Rubio-Gonzalez C, F.-M.C., Gomez-Rosas G, Ocana JL, Morales M, Porro JA, Effect of laser shock processing on fatigue crack growth of duplex stainless steel. Mater Sci Eng A, 2011(528): p. 914-919.

[18]. Rubio-Gonzalez C, O.J., Gomez-Rosas G, Molpeceres C, Paredes M, Banderas A, et al, Effect of laser shock processing on fatigue crack growth and fracture toughness of 6061-T6 aluminum alloy. Mater Sci Eng A, 2004(5): p. 291-295.

[19]. Zhou JZ, H.S., Sheng J, Lu JZ, Wang CD, Chen KM, et al, Effect of repeated impacts on mechanical properties and fatigue fracture morphologies of 6061- T6 aluminum subject to laser peening. Mater Sci Eng A 2012(539): p. 360-368.

[20]. Zhang XC, Z.Y., Lu JZ, Xuan FZ, Wang ZD, Tu ST., Improvement of fatigue life of Ti-6Al-4V alloy by laser shock peening. Mater Sci Eng A 2010(527): p. 3411-3415.

[21]. Yang JM, H.Y., Han NL, Laser shock peening on fatigue behavior of 2024-T3 Al alloy with fastener holes and stopholes. Mater Sci Eng A 2001(298): p. 296-299.

[22]. Warren AW, G.Y., Chen SC. , Massive parallel laser shock peening: simulation, analysis, and validation. Int J Fatigue, 2008(30): p. 188-197.

[23]. Gomez-Rosas G, R.-G.C., Ocana J L, Molpeceres C, Porro J A, Morales M, etal., Laser shock processing of 6061-T6 Al alloy with 1064nm and $532 \mathrm{~nm}$ wavelengths. Applied Surface Science, 2010(256): p. 5828-5831.

[24]. Rubio-Gonzalez C, O.J.L., Gomez-Rosas G, Molpeceres C, Paredes M, Banderas A, et al, Effectoflasershockprocessingonfatiguecrackgrowth and fracturetoughnessof6061T6aluminumalloy. Materials Science and Engineering A, 2004(386): p. 291-295.

[25]. MutomboK, T.-D., Corrosion fatigue behaviour of aluminum alloy 6061-T651 welded using fully automatic gas metal arc welding and ER5183 filler alloy. International Journal of Fatigue, 2011(33): p. 1539-1547. 
[26]. Zhang Y K, L.J.Z., Ren X D,Yao H B, Yao H X., Effect of laser shock processing on the mechanical properties and fatigue lives of the turbo jet engine blades manufactured by LY2 aluminum alloy. Materials and Design, 2009(30): p. 1697-1703.

[27]. Liu K K, H.M.R., The effects of laser peening and shot peening on fretting fatigue in Ti-6 Al-4 Vcoupons. Tribology International, 2009(42): p. 1250-1262.

[28]. LuJZ, Z., FengAX,JiangYF,ChengGG., Effects of laser shock processing on mechanical properties of Fe-Ni alloy. Materials and Design, 2009(30): p. 3673-3678.

[29]. NikitinI, A., Comparison of the fatigue behavior and residual stress stability of lasershock peened and deep rolled austenitic stainless steel AISI3O4 in the temperature range25-600 1C. . Materials Science and Engineering A, 2007(465): p. 76-82.

[30]. Hu Y, Y.Z., Overlapping rate effect on laser shock processing of 1045 steel by small spots with Nd:YAG pulsed laser. Surface and Coatings Technology 2008(202): p. 1517-25.

[31]. Sano Y, O.M., Kubo T, Mukai N, Yoda M, Masaki K, etal, Retardation of crack initiation and growth in austenitic stainless steels by laser peening without protective coating. Materials Science and Engineering A, 2006(334): p. 334-340.

[32]. Sano Y, M.N., Okazaki K, Obata M, Residual stress improvement in metal surface Irradiation by underwater laser. Nuclear Instruments and Methodsin Physics Research B, 1997(121): p. 432-436.

[33]. K. Ding, L.Y., Laser Shock Peening: Performance and Process Simulation. First ed. Woodhead Publishing, Cambridge, 2006.

[34]. N. Mukai, N.A., M. Obata, A. Ito, Y. Sano, C. Konagai, in, Proceedings of the Third JSME/ASME International Conference on Nuclear Engineering (ICONE-3), Kyoto, 1995.

[35]. P. Peyre, R.F., P. Merrien, H.P. Lieurade, Mater. Sci. Eng. A, 1996(210).

[36]. U. Trdan, J.L.O., J. Grum, , J. Mech. Eng. , 2010(385).

[37]. M. Obata, Y.S., N. Mukai, M. Yoda, S. Shima, M. Kanno, Proceedings of the Seventh International Conference on Shot Peening (ICSP7), Warsaw, 1999: p. 387-394.

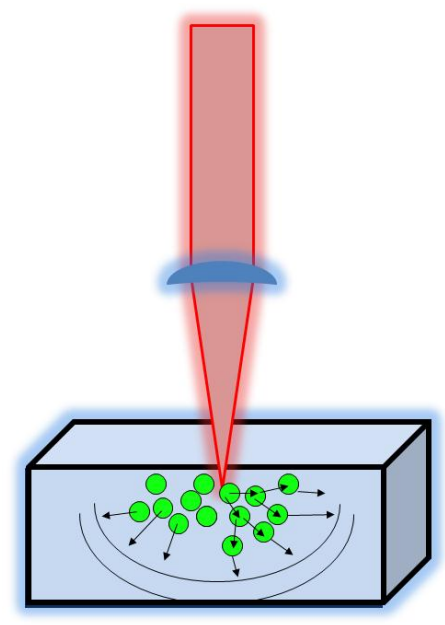

Fig. 1: Schematic representation of basic process of laser shock peening of samples 


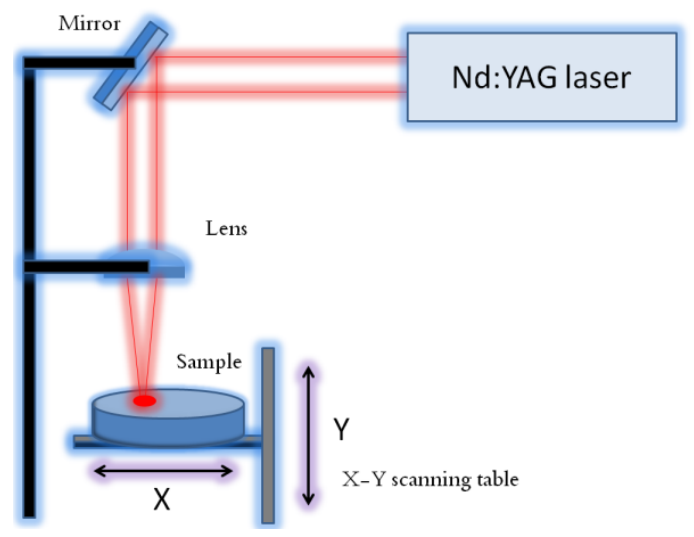

Fig. 2: Schematic representation of experiment setup

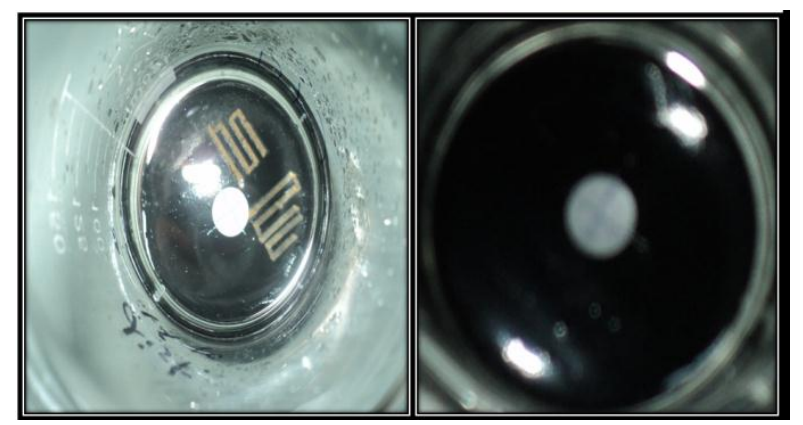

Fig. 3: Schematic representation of the sample before and after the effect of LSP.

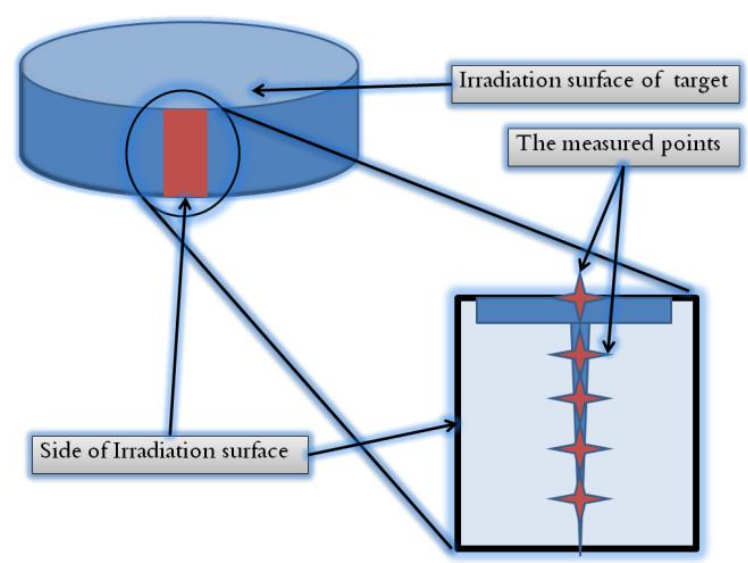

Fig. 4: Schematic representation of Vickers micro hardness is used the hardness effects from LSP. 


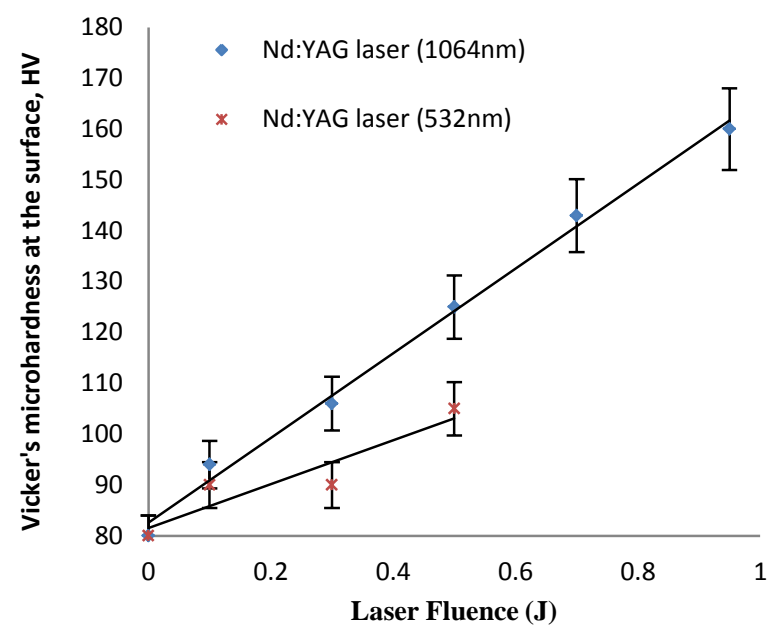

Fig. 5: Vickers micro hardness as a function of energy fluence for nanosecond laser.

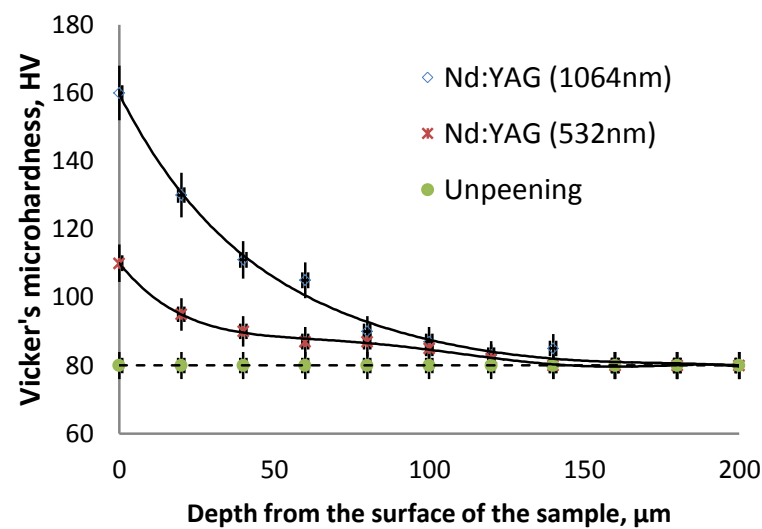

Fig. 6: Vickers micro hardness as a function of depth for nanosecond laser.

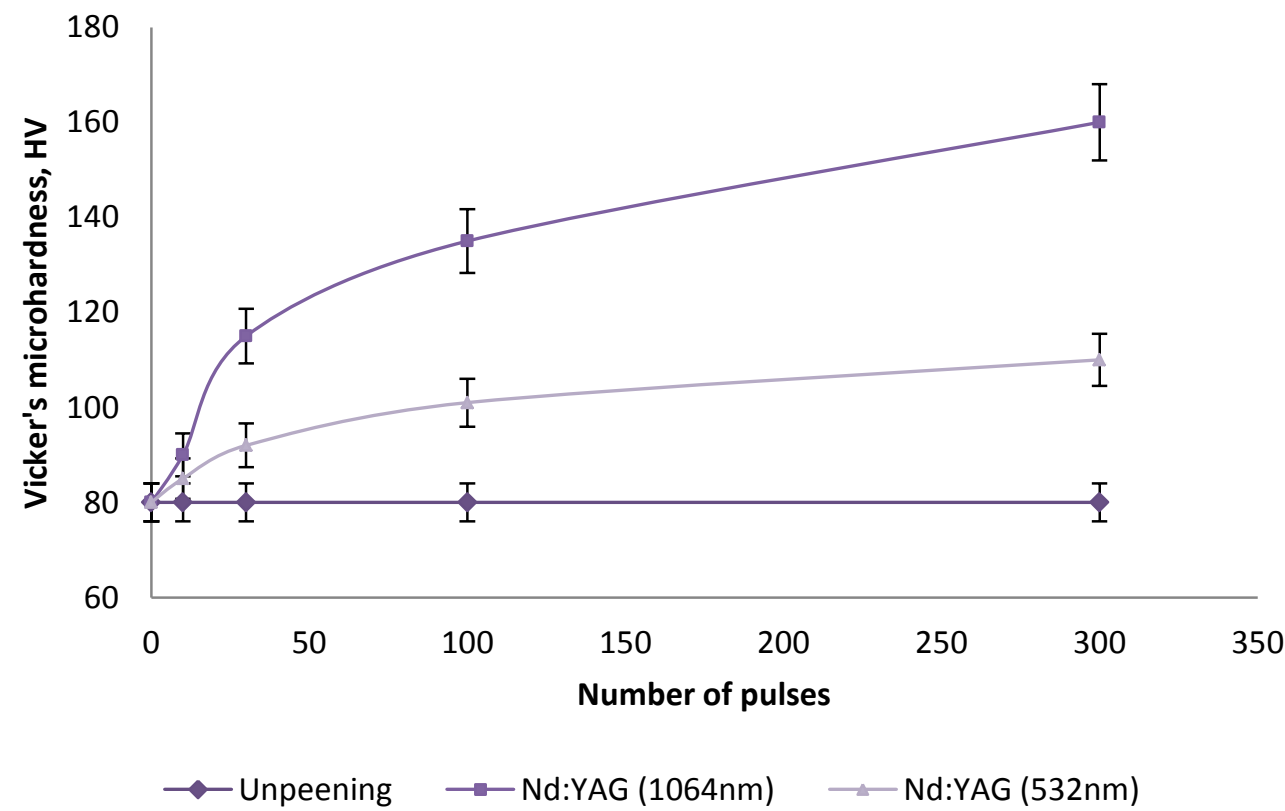

Fig. 7: Vickers micro hardness as a function of number of pulses. 
Table 1: Experimental parameters of laser peening without coating ( $\mathrm{LPwC}$ ).

\begin{tabular}{l|l}
\hline \multicolumn{1}{c|}{ Experimental parameters } & \multicolumn{1}{c}{ Values } \\
\hline Pulse energy $\left(\mathrm{E}_{\mathrm{p}}\right)$ & $0.1: 0.9 \mathrm{~J}$ \\
Laser spot diameter $(\mathrm{D})$ & $15 \mathrm{~mm}$ \\
Pulse density $\left(\mathrm{N}_{\mathrm{p}}\right)$ & $300 \mathrm{pulse} / \mathrm{mm}^{2}$ \\
FWHM $(\mathrm{T})$ & $7 \mathrm{~ns}$ \\
Diameter of the central spot $\left(\mathrm{d}_{\mathrm{min}}\right)$ & $11.4 \mu$ for $\lambda=1.064 \mu \mathrm{m}$ \\
Peak power density $(\mathrm{G})$ & $30 \mathrm{TW} / \mathrm{cm}^{2}$ \\
\hline \hline
\end{tabular}

